\title{
Learning to use transit services: adapting to unfamiliar transit travel
}

\author{
Lorelei Schmitt $^{1} \cdot$ Alexa Delbosc $^{2}$ (D) $\cdot$ Graham Currie $^{2}$
}

Published online: 14 May 2018

(C) The Author(s) 2018

\begin{abstract}
Travel behavior change has become an area of interest in many cities around the world, particularly to encourage people to change from car use to transit use. Previous research indicates that habits can act as a barrier to travel behavior change and that new use of transit can be associated with some negative characteristics such as increased anxiety and difficulty with wayfinding. However, thus far little research has focused on gaining an in-depth understanding of the process of travel behavior change from the perspective of the new transit user. The present research seeks to fill this gap through a rich qualitative exploration of the process of undertaking 'new' (to the participants) journeys on transit, how this experience differs from familiar or habitual travel, and the process of learning and habituation that is undertaken as unfamiliar travel is repeated and evolves into familiar travel. This is achieved by using Grounded Theory to collect and interpret data from 30 semi-structured interviews where participants described both familiar and unfamiliar trip experiences in their own words. The process of undertaking unfamiliar transit travel is characterized by a number of barriers and obstacles and it is characterized by uncertainty and anxiety. If unfamiliar travel is repeated, a change process occurs which includes a number of cognitive processes and adaptations to streamline the process of travel. From the findings, a number of recommendations to support long term travel behavior change are identified.
\end{abstract}

Keywords Transit · Public transport - Qualitative research · Unfamiliar travel · First trips

Alexa Delbosc

alexa.delbosc@monash.edu

1 Opus International Consultants, L10 Majestic Centre, 100 Willis St, Wellington 6144, New Zealand

2 Monash University, 23 College Walk, Clayton, VIC 3800, Australia 


\section{Introduction}

World-wide there has been much research and investment in trying to promote travel behavior change, especially from car-driving to transit use. This has often been through the form of strategies like marketing, travel plans, personalized journey planning and other travel demand management techniques aimed at understanding why people travel by certain modes and how we can support them to change behavior. However, little research directly examines the experience of being a new or 'unfamiliar' transit traveler. Little is known about how this experience differs from familiar transit travel or the iterative process that is required to learn how to use a new transit service.

Previous research shows that travel habits can act as a barrier to travel behavior change (e.g. Verplanken et al. 1994; Verplanken and Aarts 1999; Klockner and Matthies 2004; Ramadurai and Srinivasan 2006) and that new use of transit can be associated with some negative characteristics such as increased anxiety and difficulty with wayfinding (Schmitt et al. 2013, 2015). Some research also examines instances when habitual travel is disrupted, such as freeway closures (e.g. Fujii et al. 2001) and through life events (Clark et al. 2014). However, thus far little research focuses on the change process itself. How does the process of learning and habituation to new travel behaviors take place, despite obstacles and challenges like anxiety and wayfinding issues? Moreover, little research in this area has been undertaken from the perspective of travelers, allowing research participants to describe, in their own words, their new transit travel experiences.

This paper attempts to fill these research gaps by offering an in-depth examination of unfamiliar transit travel. Three aims emerged during the course of the research:

1. To understand the process of undertaking unfamiliar transit travel.

2. To explore how the experience of undertaking unfamiliar transit travel differs from familiar travel.

3. To understand the process of learning and habituation that takes place as unfamiliar travel is repeated and evolves into familiar travel.

All three of these aims were examined from the perspective of transit system users. These aims were achieved by drawing on qualitative depth interviews conducted in Melbourne, Australia and analysed using Grounded Theory.

This paper is structured as follows. It begins with a review of the existing literature on unfamiliar transit travel and the process that people undertake in learning to use unfamiliar services. It then contains a description of the study context and the methodology employed in conducting and analyzing the qualitative interviews. This is followed by a discussion of the key results from the qualitative research. The paper finishes with a discussion of the study findings and implications for practice and future research.

\section{What do we know about unfamiliar transit travel?}

Attracting and retaining transit passengers can be challenging (Banister 2008). A better understanding of the processes underlying travel decision-making can help make transit services more attractive to potential new users and existing users. Research suggests that day-to-day travel behaviour actually involves very little decision-making but rather is 
largely based on habit (Verplanken et al. 1994; Klockner and Matthies 2004; Ramadurai and Srinivasan 2006). This can range from habitual travel modes right through to habitually using specific routes. In general, people tend to prefer familiar travel modes and even familiar travel routes (Bovy and Stern 1990). In fact it is not uncommon for people to travel by a familiar means even if there is a potentially shorter but unfamiliar way (Bovy and Stern 1990). Even with navigational aids, people may prefer familiar environments due to unknowns associated with the unfamiliar route. Yet for a new travel choice to be made, an old travel habit must be broken.

There is an array of circumstances which may lead to new transit use. These changes may be made voluntarily, for example through tourism experiences (Le-Klähn et al. 2014), changes or the introduction of new transit services (Chatterjee and Ma 2009; Nordlund and Westin 2013) or the provision of free transit passes (Bamberg and Schmidt 1999; Gould and Zhou 2010). They may also be undertaken wholly or partially involuntarily, through changes in the generalized cost of road transport such as rising petrol prices (Lane 2010), freeway closures (Fujii et al. 2001) or temporary loss of access to driving or a car (Kuhnimhof et al. 2006).

One particularly well-studied prompt for reassessing travel habits are life events, such as starting a new job, having a baby or moving houses (Beige and Axhausen 2012; Clark et al. 2014). These events can disrupt travel habits but are relevantly uncommon. Beige and Axhausen (2012) found that household changes (e.g. moving out of parent's home, births and marriages) occur for less than $2 \%$ of the population in a given year whereas changes in employment, residence and education occur among $15 \%$ of respondents per year. Employment changes, residential relocation, retirement and the birth of children are all associated with changes to car ownership and commute mode (Clark et al. 2014).

Another area of research into changing travel habits comes from the travel demand management literature. In particular, there is a school of thought that encouraging people to try public transport (through free passes or promotions) may correct misinformation and reduce the gap between pre-conceived perceptions of public transport and reality (Taylor 2007; Thøgersen 2009; Gould and Zhou 2010). Undertaking unfamiliar transit travel helps patrons learn about the services which, in turn, has the potential to make the service easier for them to use. Knowledge gained from trialling transit travel may reduce the amount of cognitive effort required for subsequent trips by increasing familiarity of the associated system and environment (Stradling 2002). It may also reduce the psychological barriers by reducing uncertainty. These knowledge gaps may be significant barriers to long-term behaviour change if the effort to learn a new mode is deemed to be 'too hard', yet there is little research on this learning experience from the perspective of the traveller.

\section{The experience of unfamiliar transit travel}

Although there is a wealth of existing literature related to travel habits and the circumstances that might disrupt them, there is less research focusing specifically on the experience of non-habitual and unfamiliar travel. Habitual travel requires very little cognitive effort; it provides a "smoothness and fluency" to behavior (Verplanken 2006). In contrast, unfamiliar travel is likely to be experienced very differently with risks of embarrassment, making mistakes and increased cognitive effort (Stradling 2002; Schmitt et al. 2015). Travelers using unfamiliar transit routes were generally more anxious, even if they were frequent transit users (Schmitt et al. 2015). 
Wayfinding is one aspect of an unfamiliar travel experience which is relatively well-documented. Prestopnik and Roskos-Ewoldsen (2000) argue that wayfinding involves complex cognitive processes. These processes may include remembering street names, locations of streets and landmarks, how streets lay in relation to one another, and how the locations of these are all related to the location of the traveler.

Dziekan (2008) used a study of overseas exchange students to study the process of adjusting to wayfinding in an unfamiliar transit environment. The author poses a 3-stage 'phases of learning' approach captured in Table 1. Phase 1 is an 'alert phase' when everything is new and the cognitive effort of wayfinding can be tiring. One is establishing a cognitive map through extensive information gathering from a variety of sources and beginning to fix reference points. Phase 2 is characterized by having some background cognitive spatial reference, growing feelings of familiarity and confidence, using navigational tools like maps and signs primarily for confirmation and reassurance, and beginning to optimize daily travel. The third and final phase is characterized by feelings of competence to navigate the system with a larger number of meaningful reference points and a better understanding of the logic underlying the transit system.

This research uses the most extreme case of unfamiliar transit travel—the first time using a system in a completely different country. It is unclear whether a similar learning process occurs in less extreme cases, such as using a new mode in a familiar city, or even using a new route on a familiar mode.

The present research builds on these past studies by examining the process of learning to use unfamiliar transit trips using in-depth interviews in Melbourne, Australia. Rather than focus on a specific type of new transit trip (such as new visitors to a city), this research took a broader definition of 'unfamiliar transit travel' (from a new route to a new city) to uncover similarities across a range of unfamiliar travel experiences.

\section{Methodology}

\section{Research context}

This research was undertaken in Melbourne, a city of over 4 million and the capital of the state of Victoria in Australia. In terms of land use, the city center, or Central Business District (CBD), has a fairly high density of employment and residence which is surrounded in closer proximity by medium density development, which then gives way to low density suburbs further from the CBD. It is served by a radial heavy rail system connecting the inner city to the suburbs and a largely radial streetcar network in the inner and middle suburbs. The bus system provides local and orbital transit links in middle and outer suburbs.

Although the interviews took place in Melbourne and largely concern the Melbourne transit network, interviewees often referred to experiences when travelling on transit systems in other states or overseas.

\section{Grounded theory and research direction}

Many authors argue that because travel behavior is complex, qualitative research methods are an important tool to allow individuals to provide their own explanations of their perceptions and behaviors (e.g. Beirão and Sarsfield Cabral 2007). This research approach provides for a rich exploration of unfamiliar transit travel which enabled 


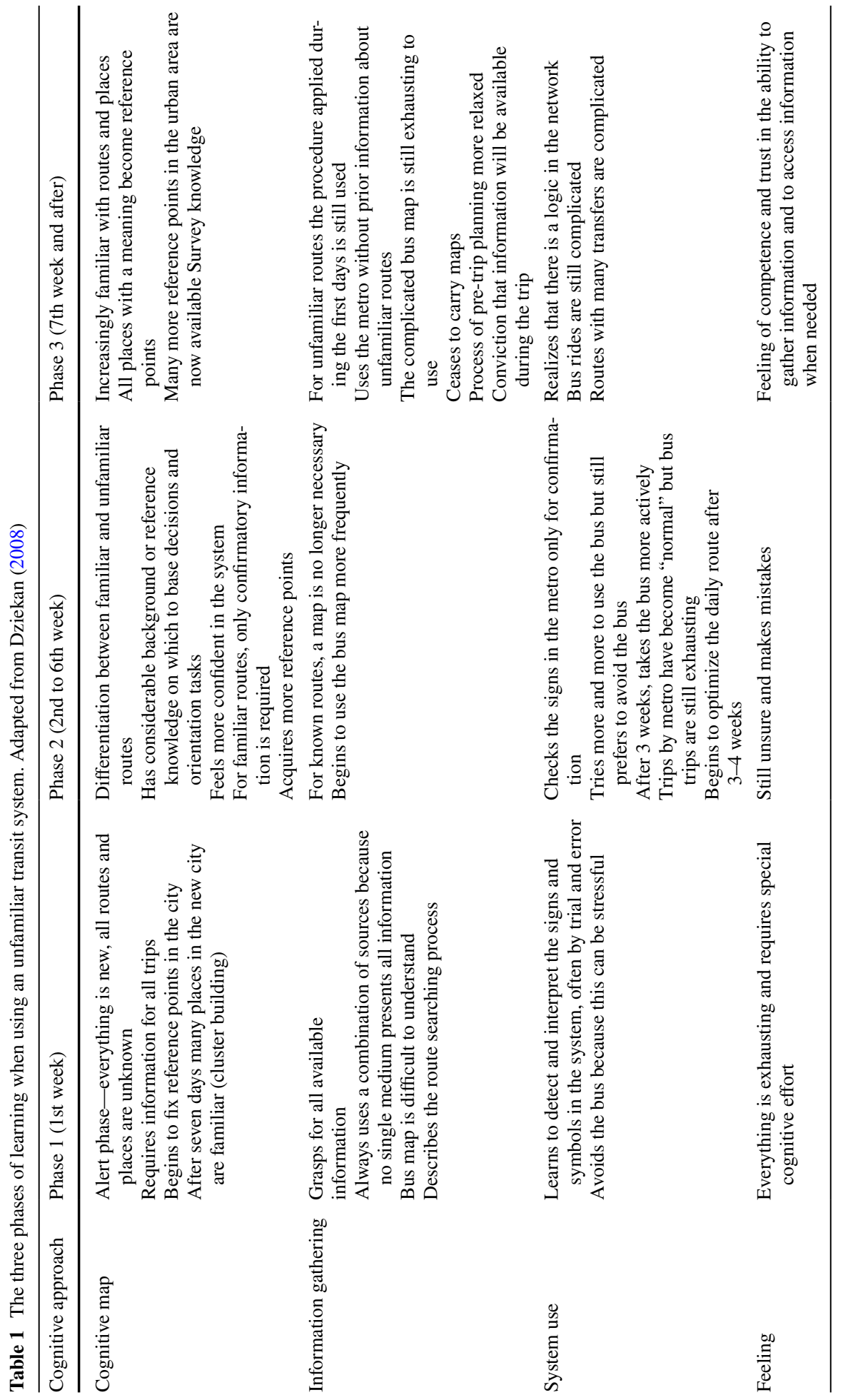


participants to identify important aspects of unfamiliar travel that may not have been captured, or emerged, through sole reliance on survey questions. This is because survey questions can be somewhat prescriptive and thus inadvertently prevent participants from reporting aspects like idiosyncrasies, learning strategies and adaptive processes.

In understanding the context of this research method, it is important to firstly understand that the qualitative research tool, 'Grounded theory', guided the research design. Grounded theory research often begins with no research objectives or very broad research objectives. This is because grounded theory research involves an adaptive process whereby the researcher refines the research objectives from prominent and/or interesting themes as they emerge from the initial data (Charmaz 1995; Morse 2009). Thus, at the outset of undertaking the interviews, the research objectives were somewhat broad and were designed as an exploratory examination of unfamiliar transit travel.

Grounded theory also tends to involve delaying the literature review (Charmaz 2006). While some literature was reviewed prior to the interviews, there was actually very little research about unfamiliar transit travel, and the most relevant study to the present research (e.g. Dziekan 2008), was only identified after the interviews were conducted.

Care was taken to structure the interviews in an open way, which allowed interviewees a platform to provide open-ended descriptions of their transit travel. The interviews were semi-structured to allow participants to describe what they felt was important. Participants were first asked to describe a transit journey that they undertake regularly (or have undertaken regularly in the past) and then to describe their first time undertaking that journey. If they could not recall their first time taking that trip, they were asked to describe another unfamiliar transit journey that they could remember then they were requested to describe further unfamiliar journeys.

A recurring issue encountered in examining unfamiliar travel is defining exactly what unfamiliar travel is. In the qualitative discussions, participants generally discussed unfamiliar travel in the context of using a particular transit service (such as a specific bus route) for the first time. However, the degree of unfamiliarity ranged from the most unfamiliar (e.g., first time using any service in a new city) to the least unfamiliar (e.g., going to a new stop on a familiar route or adjusting to a new ticketing system).

The unfamiliar travel captured in this paper included any types of unfamiliar travel that participants wished to discuss (i.e. for a range of purposes) but participants largely described habitual travel for commuting, travel related to life events (when they started the habitual commuting behavior) and travel overseas. A number of prompts were available to the interviewer to ask for more details about elements of trips if participants needed them. In line with grounded theory principles (Charmaz 1995), it was expected that as the interviews progressed some elements of the research topic might emerge as particularly worthwhile to explore further during the interviews.

Thus, the emergent theme from these interviews centered on understanding the process of learning and habituation that takes place as unfamiliar travel is repeated and evolves into familiar travel. Aspects of this theme were thus discussed in more detail in later interviews.

After gaining consent from participants to do so, all interviews were audio-recorded. In practicing grounded theory, analysis tends to begin with individual cases or experiences and develops towards abstract conceptual categories which can help to explain and synthesize the data (Charmaz 1995). The first half of interviews were transcribed verbatim and 'line-by-line' coding was undertaken (a Grounded Theory method of analysis which involves noting the key emergent theme for each line of text). Later interviews were not transcribed in full, rather transcription focused on elements related to emergent themes and 
the potentially relevant variables (e.g. circumstances of trips like trip purpose that may have impacted experiences).

\section{Recruitment}

Potential participants were recruited from a pool of respondents to a survey on access to the Monash University campus (Schmitt et al. 2013). Some 121 survey respondents indicated they were willing to participate in further research and of those, a total of 30 interviews were conducted, one with each of 30 participants, and each interview was approximately $20 \mathrm{~min}$ in length. The first set of interviews were undertaken over 6 weeks (August 2012-September 2012) which allowed for some interim analysis between interviews and adaptation of interview styles consistent with 'grounded theory' principles of qualitative research. A second set of interviews, utilizing an updated set of research questions, was then performed (April 2013-June 2013) to allow for additional data collection.

The demographics of participants are presented in Table 2. Participants ranged in age from 18 to over 60, had a range of experience with transit and tended to have lived in Melbourne for over 10 years (although some were more recently arrived). It is clear that there is some over-representation of females and participants in middle and younger age groups, this is likely due to the recruitment method (primarily from a university population). Initial sampling from the survey pool was random but there was some over-representation of frequent transit users, so more targeted sampling was employed for later interviews in order to attract more car-dependent participants, stratifying the sample. This variable was particularly important due to the nature of the research: there could be differences in how frequent transit users experience unfamiliar transit journeys to those who rarely use transit. Data collection stopped when no new themes were emerging and data saturation was reached.

\section{Results}

This section describes key results from the in-depth interviews with regard to unfamiliar transit travel. It begins by describing the process of undertaking unfamiliar travel before emphasizing key differences between the experience of familiar and unfamiliar transit travel. It finishes with a description of the habituation process that takes place during the familiarization process.

\section{The process of undertaking unfamiliar travel}

The experience of unfamiliar travel can be synthesized into a clear set of steps, summarized in Fig. 1. As mentioned in the methodology section, the context of unfamiliar transit travel can vary from using a new part of a familiar system all the way to being new to a city, which in turn has implications for the barriers to undertaking a new trip on an unfamiliar transit system. These barriers can include a lack of understanding of the system (where to go, how to pay, how much to pay) as well as the associated anxiety and uncertainty this unfamiliarity can bring. These barriers can be significant, particularly in combination, and depending on the circumstances they may keep some people from using an unfamiliar transit mode altogether.

However, it was clear from interviews that most travelers are not passive to these barriers; rather they actively manage them through a range of risk-mitigation strategies such 
Table 2 Respondent demographics

\begin{tabular}{|c|c|c|c|c|c|c|}
\hline Alias & $\begin{array}{l}\text { Time living in mel- } \\
\text { bourne }\end{array}$ & $\begin{array}{l}\text { Car/motorbike } \\
\text { mode share }(\%)\end{array}$ & $\begin{array}{l}\text { Transit } \\
\text { mode share } \\
(\%)\end{array}$ & Gender & Age & $\begin{array}{l}\text { Annual pre-tax income } \\
\text { (AUD) }\end{array}$ \\
\hline $\mathrm{A}$ & $>10$ years & 20 & 30 & Male & $61+$ & $\$ 72,800-\$ 103,999$ \\
\hline AA & $5-10$ years & 0 & 30 & Male & $31-40$ & $\$ 104,000$ or more \\
\hline B & $>10$ years & 75 & 20 & Female & $51-60$ & $\$ 36,400-\$ 51,999$ \\
\hline BB & $>10$ years & 10 & 88 & Male & $41-50$ & $\$ 52,000-\$ 72,799$ \\
\hline $\mathrm{C}$ & $>10$ years & 60 & 40 & Female & $18-24$ & $\$ 1-\$ 20,799$ \\
\hline $\mathrm{CC}$ & $>10$ years & 75 & 15 & Female & $51-60$ & No response \\
\hline $\mathrm{D}$ & $>10$ years & 0 & 95 & Male & $51-60$ & $\$ 104,000$ or more \\
\hline DD & $2-5$ years & 0 & 90 & Female & $31-40$ & $\$ 20,800-\$ 36,399$ \\
\hline $\mathrm{E}$ & $>10$ years & 30 & 60 & Female & $61+$ & $\$ 36,400-\$ 51,999$ \\
\hline $\mathrm{F}$ & $>10$ years & 80 & 10 & Male & $18-24$ & $\$ 1-\$ 20,799$ \\
\hline G & $5-10$ years & 5 & 70 & Female & $31-40$ & $\$ 72,800-\$ 103,999$ \\
\hline $\mathrm{H}$ & $>10$ years & 80 & 15 & Female & $51-60$ & $\$ 36,400-\$ 51,999$ \\
\hline I & $>10$ years & 9 & 52 & Female & $31-40$ & $\$ 52,000-\$ 72,799$ \\
\hline $\mathrm{J}$ & $>10$ years & 0 & 85 & Male & $25-30$ & $\$ 20,800-\$ 36,399$ \\
\hline $\mathrm{K}$ & $2-5$ years & 1 & 9 & Female & $18-24$ & Nil income \\
\hline $\mathrm{L}$ & $2-5$ years & 0 & 80 & Female & $18-24$ & Nil income \\
\hline M & $>10$ years & 90 & 2 & Female & $25-30$ & $\$ 52,000-\$ 72,799$ \\
\hline $\mathrm{N}$ & 6 months -2 years & 40 & 20 & Male & $25-30$ & $\$ 20,800-\$ 36,399$ \\
\hline $\mathrm{O}$ & $2-5$ years & 80 & 0 & Female & $31-40$ & $\$ 1-\$ 20,799$ \\
\hline$P$ & $>10$ years & 80 & 20 & Female & $31-40$ & $\$ 52,000-\$ 72,799$ \\
\hline Q & 6 months-2 years & 95 & 3 & Female & $31-40$ & $\$ 72,800-\$ 103,999$ \\
\hline $\mathrm{R}$ & 5-10 years & 10 & 20 & Female & $25-30$ & $\$ 36,400-\$ 51,999$ \\
\hline$S$ & $>10$ years & 20 & 60 & Female & $41-50$ & $\$ 72,800-\$ 103,999$ \\
\hline $\mathrm{T}$ & 6 months-2 years & 0 & 10 & Male & $25-30$ & $\$ 1-\$ 20,799$ \\
\hline $\mathrm{U}$ & $>10$ years & 10 & 80 & Female & $51-60$ & $\$ 36,400-\$ 51,999$ \\
\hline V & $>10$ years & 90 & 0 & Female & $31-40$ & Nil income \\
\hline W & $>10$ years & 90 & 0 & Female & $51-60$ & $\$ 52,000-\$ 72,799$ \\
\hline $\mathrm{X}$ & $>10$ years & 14 & 29 & Female & $51-60$ & $\$ 72,800-\$ 103,999$ \\
\hline $\mathrm{Y}$ & $>10$ years & 10 & 80 & Female & $18-24$ & $\$ 1-\$ 20,799$ \\
\hline $\mathrm{Z}$ & 5-10 years & 10 & 20 & Female & $31-40$ & $\$ 20,800-\$ 36,399$ \\
\hline
\end{tabular}

as planning, asking for help and using easier-to-navigate modes. These behaviors could be thought of as 'unfamiliar trip enablers.' One particularly prominent contrast between unfamiliar and familiar travel was how much pre-trip planning was required for unfamiliar use versus how much information familiar travelers already knew about their travel options and services they were using. For unfamiliar travel, many of the interviewees described undertaking relatively extensive information gathering to reduce anxiety and uncertainty:

I do use PTV Journey Planner ${ }^{1}$ a fair bit; if I am going somewhere new and I am not sure how to get there I will use PTV Journey Planner and sort of work things

1 PTV stands for Public Transport Victoria, the umbrella organisation for public transport in Melbourne. 


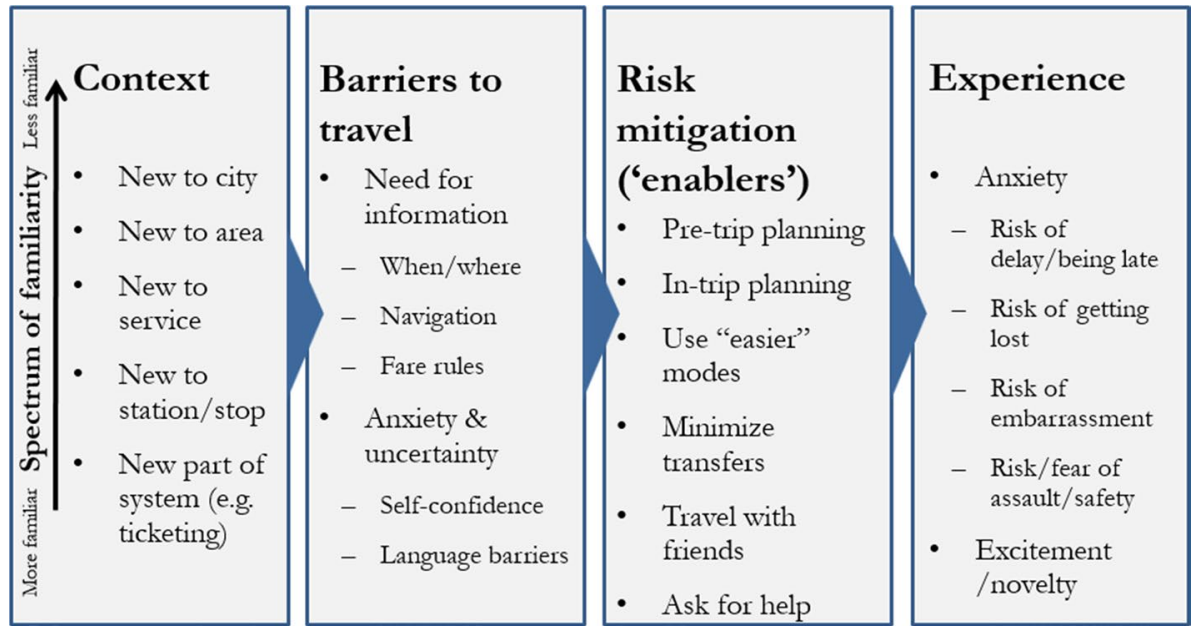

Fig. 1 The process of unfamiliar transit travel

out... And I had gone on Journey Planner to figure it all out and even looked on the [Google] Map street directory so that I could look at the landmarks around the area so that if I was looking out the bus window when I would be able to go "well, that's the shop that I saw in [Google] Map. (Interview G)

Some modes were characterized as easier to navigate for unfamiliar trips; in particular, trains and streetcars were described as easier to understand than buses, which they perceived to be difficult for wayfinding:

I think if I'm unfamiliar with a city or an area I would prefer to catch a train because you can have the map and you know the secrets of stops and then you basically only get into trouble if the train starts skipping a whole bunch of stations and you can't get off whereas I think with buses it's a lot harder to orient yourself, I mean there might be stop numbers but you probably haven't got a map that gives you an indication of where those stops are. (Interview DD)

In this quote we see how context, like level of familiarity with a city or transit system (i.e. the 'spectrum of familiarity' in Fig. 1) impacts the degree of barriers and importance of enablers like maps and easier-to-navigate transit services (i.e. trains), leading to risk-mitigating behaviour (i.e. choosing to take the train) and associated experiences (reduced anxiety etc.). This relationship is captured by Fig. 1 and reiterates the importance of the columns in Table 1 related to length of time living in a city and background travel habits.

It is worth noting that even when employing risk mitigation strategies, the experience of undertaking unfamiliar travel was often characterized by anxiety or, to a lesser extent, excitement. This difference is explored in greater depth in the next section. 


\section{Key differences between familiar and unfamiliar transit travel}

Interviews revealed a range of key differences between familiar and unfamiliar transit travel, including differences in emotional state, wayfinding and activities undertaken whilst travelling. Familiar trips are described as somewhat boring, repetitive tasks where people can let their minds wander. People tended to describe sleeping, dozing, reading, studying foreign languages, playing games on their phones, looking out the window, and listening to music. Familiar travelers overwhelmingly described doing activities generally unrelated to the trip itself including reading, relaxing and other activities. Many of the interviewees described their journeys as a unique opportunity for downtime to do such activities in the midst of their busy lives. Though occasionally people described an interest in looking out the window for familiar travel, many described not noticing the journey itself:

It's just, you get used to it when you've done it so often and you start to just not see anything because it's so familiar. The things that you probably would notice are the things that have changed or change in the traffic mostly [her bus route is on a busy road with no priority] you notice if it's busier than usual mostly because it affects your travel to work (Interview $\mathrm{Z}$ describing her journey to work).

In contrast, unfamiliar transit travel is experienced very differently. The experience is characterized by heightened information-gathering, wayfinding and emotions. As described in the previous section, people often spent time pre-planning their trip and during the journey they undertook an active process of wayfinding. This is perhaps one of the most prominent experiential characteristics of unfamiliar travel. For example:

I kept looking, 'is this the street? Is this the street?' because I didn't really know the area. I knew a bit of it but then it went into a part I didn't know and it's just looking at all the street signs. I knew what street I had to get off at, so I was just constantly on the alert for most of the time really. (Interview W).

Because of this active process, travelers undertook very different activities during unfamiliar trips; rather than relax, read, or doze, they were in a constant state of vigilancereading maps, looking for signs or observing scenery. A range of strategies were employed to improve wayfinding, such as intense information gathering (trip planning, use of maps, etc.), asking for help or using modern technology such as smartphone GPS. Yet despite these strategies, a number of people reported making mistakes while undertaking unfamiliar transit, often in wayfinding. These mistakes can range from minor inconvenience and embarrassment (such as walking the wrong way in a train station) to getting lost for substantial periods of time:

[When I moved to Canberra], I did catch the wrong bus a couple of times and end up somewhere lost in the suburbs so I had no idea where I was and didn't have a smartphone at that stage and couldn't even lookup where I was (Interview DD).

As a result of this heightened sensitivity to surroundings, the emotional state during unfamiliar journeys was often very different to a familiar journey. Unfamiliar transit trips tended to have heightened emotional levels and were characterized primarily by anxiety or excitement. Often anxiety was related to wayfinding, however sometimes it was associated with the purpose of the trip, especially if the unfamiliar journey was related to a significant life event such as a job interview. 
I'm usually nervous if I don't know what I'm doing. Yeah particularly if I have to do it by myself which I don't usually have to, usually there's someone else there that knows what we're doing. But yeah I would get nervous if I think that, I'm going to miss my stop and not know how to get back (Interview R).

Other times unfamiliar travel was associated with excitement or novelty, especially when the travel took place in a new city or whilst on holidays overseas.

It was exciting and it was a novelty and it was really fun and we couldn't wait for our family to come over so that we could show them the trams and all that sort of stuff. (Interview Z, after moving to Melbourne).

Thus, in some instances people felt feelings of excitement associated with unfamiliar travel, primarily related to getting to explore and learn about a different area. In contrast, participants tended to provide little description for emotions associated with familiar travel other than apathy, boredom and frustration. For example:

I don't think I had really strong emotions or really strong perception of any particular good or bad thing about the train...I mean, it was just the train (Interview O).

In some instances, participants described how their own personal characteristics influenced their unfamiliar travel experiences. For example, Interview A described having an intrinsic interest in public transport and feels comfortable using unfamiliar travel in other states. Meanwhile, some interviewees revealed self-ratings of their navigational abilities and strategies and described how these influence their unfamiliar travel experiences:

I wouldn't say that I've got a good sense of direction but I kind of pay attention where I'm going so I know how to get back in case I need to and I think travelling helps, if you've travelled a lot and you've had to get used to how to navigate in certain areas and stuff like that (Interview Z).

As I say having a really poor sense of direction, I do worry about getting lost (Interview B).

Thus, it was observed that people have perceptions about their wayfinding abilities and 'sense of direction'. It is, however, unclear if self-perceptions shaped experiences or if people's experiences shaped their self-evaluations, or if both mechanisms are at work. In general, interviewees' dispositions toward anxiety or excitement often seemed to be related to trip context (e.g. travelling overseas for leisure vs travelling to say a job interview) and level of experience in navigating transit systems. There were not any clear trends in relation to demographics such as gender or age. However, as noted by Interview $\mathrm{Z}$ above, some participants described how previous experience in learning to use transit systems and navigate can assist later unfamiliar journeys, presumably by the development of strategies that assist in successful execution of the journey.

Interviewees described some unfamiliar trips outside of Melbourne, including in areas where they did not speak the native language. There were mixed reports of how not speaking the native language impacted travel. In many instances, the (primarily English-speaking) participants were able to find others who spoke English to assist or found some aspects of systems, like wayfinding, intuitive. For instances, Interview $\mathrm{O}$ who described how in Barcelona, despite not speaking the language, it was easy to navigate due to good signage and different colored lines: 
The different colored lines, you know, I don't know the signage is really good, but that's something compared to Melbourne I think that some other large cities around the world are really much better at: the signage (Interview $\mathrm{O}$ ).

In this instance, Interviewee $\mathrm{O}$ was able to navigate due to the presence of signage, but she also found her ease of wayfinding in Spain to raise concern about the ability of visitors to her own city at home to find their way. Others did describe making mistakes navigating transit systems overseas with not speaking the native language challenging:

At the time I was $25 .$. we stood there for about an hour and....[kept asking people], "do you speak English?". "No, no no". Anyway then a man came and he did speak English.... and he said, "oh this isn't the right bus stop." And he took us down to another bus stop (Interview W describing unfamiliar travel in Greece).

In this instance, Interview $\mathrm{W}$ found navigation difficult which resulted in her making a mistake and her trip taking much longer than it would have if she had been familiar with the journey and known which bus stop to wait at.

Thus, for most respondents, speaking another language was not overly problematic for unfamiliar travel, though some had issues and/or anxiety about the issue beforehand. For most of the interviewees who were native English speakers, they felt some gratitude that English is a commonly spoken and sign-posted language and that ticket vending machines often had an English language option.

\section{The process of familiarization and habituation}

The previous sections made clear that unfamiliar travel was characterized by uncertainty, error, vigilance and a learning process as participants navigated their surroundings. In contrast, familiar transit travel was characterized as relatively dull, straightforward and repetitive.

What became clear over the course of the interviews was that unfamiliar travel did not instantly become familiar; rather, the process of familiarization took place over time. Participants made adaptations to how they undertook unfamiliar travel to optimize their experiences, experimenting with different circumstances of their travel. Some examples included: travelling at different times of day, sitting/standing in certain strategic areas (such as doors closest to the station exit), finding opportunities to minimize transfer times and so on. It is worth considering that most unfamiliar travel will have less optimization applied, thus journeys are likely to have some negative characteristics in their un-optimized state, though the importance of these adaptations would vary. Thus, it seems that there is a process of familiarization and optimization that can occur from repeated use of a transit service, as depicted in Fig. 2.

The initial journey is associated with higher levels of anxiety and cognition, then subsequent trips are somewhat familiar though people may still be optimizing their use of a service and adjusting their behaviors to best suit their needs and preferences. Finally travel becomes familiar, it is 'just travel' for people and is characterized by less thought invested in the travel itself. Because most adaptations have been made during the 'subsequent trips' phase, people simply focus on activities, not the travel itself. Slight variations within these habitual journeys (such as a delayed service) are handled with ease, although significant disruptions (such as a system shutdown) may instigate an 'unfamiliar travel process' similar to Fig. 1. The findings captured by the process of familiarization and habituation captured 


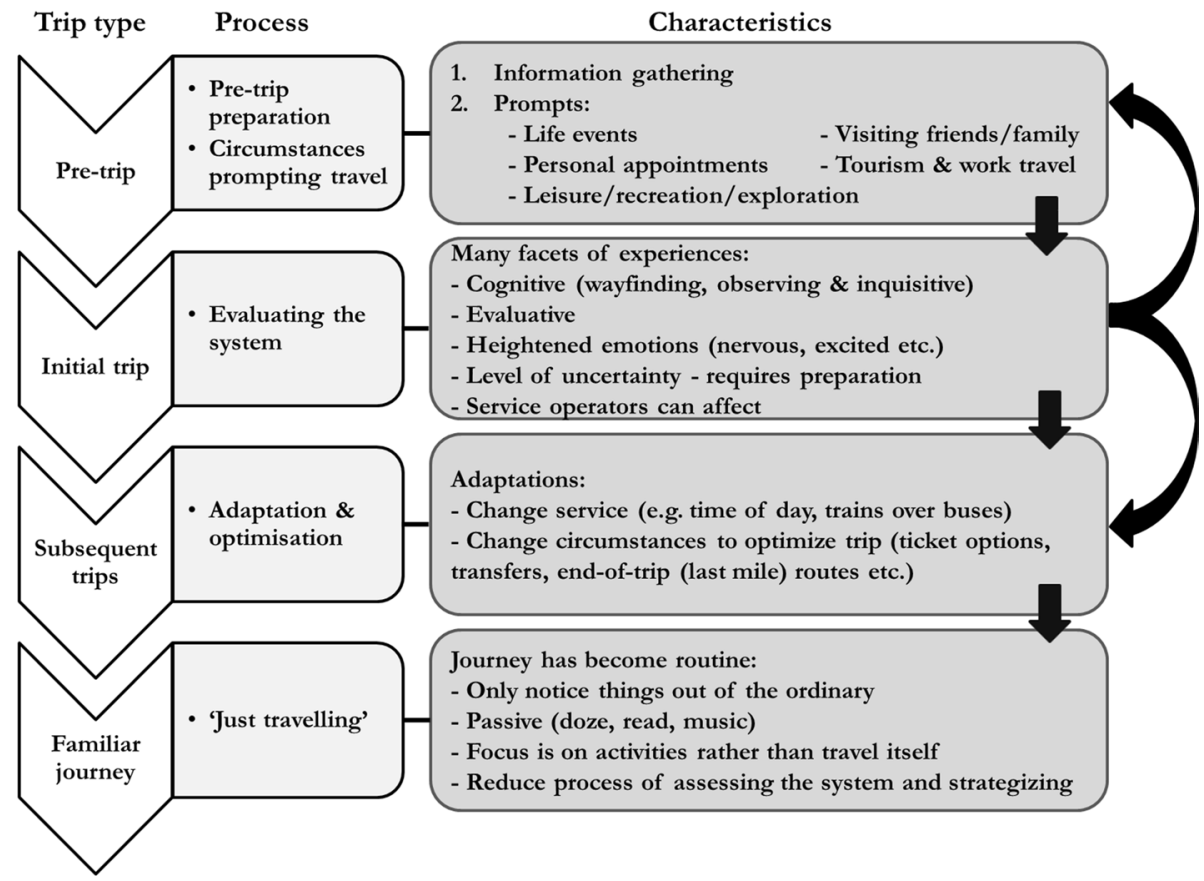

Fig. 2 Process of familiarisation and habituation

in Fig. 2 are consistent with previous research by Dziekan (2008) which were discussed in the literature review.

It should be noted that significant, unexpected disruptions did not come up often in interviews as the focus was on first trips rather than coping with unplanned disruptions to trips-in-progress. The process proposed in Fig. 2 should be interpreted primarily as a process for undertaking 'planned' trips, rather than coping with unplanned disruptions.

\section{Discussion}

This study provides a rich, in-depth understanding of the process of undertaking unfamiliar transit travel and habituating to familiar travel. The experience was largely characterized by increased uncertainty and anxiety, which supports previous quantitative research on the topic (Schmitt et al. 2013, 2015). The implication is that it is important for practitioners to implements measures that make unfamiliar travel experiences as positive as possible and reduce anxiety. If first trips are deemed to be insurmountably complex, new customers may never become repeat customers.

A number of design features to support unfamiliar transit travel (particularly wayfinding) were mentioned in the interviews: stop numbers (on the journey planner site and on signs), good directional signage, on-board stop announcements, route maps on-board and at stops/stations (including better maps on buses) and good labelling of services. Interviewees also noted that drivers and conductors that were willing to provide assistance were also appreciated. Thus, much of the information that was identified as having potential to support wayfinding is information that one would expect to be provided by transit authorities 
and operators. All this information can help to support and reinforce the cognitive map of travelers, both familiar and unfamiliar (Dziekan and Dicke-Ogenia 2010). This information is particularly useful to travelers who have a poor sense of direction or lack self-confidence.

It seems reasonable that the growing role of advanced technology may further support unfamiliar transit travel. Travel aps and real-time information can facilitate travel-decision making or even customize travel options. For example, Mobility as a Service (MaaS) simplifies unfamiliar journeys by enabling seamless planning of (and even paying for) multimodal journeys via one interface. Yet although smartphone technology can certainly assist unfamiliar travelers, locally posted wayfinding information remains imperative to provide easily accessible information to reassure unfamiliar travelers and support the development of their cognitive maps.

The amount of localized information required for new journeys suggests that programs that involve 'buddies' or personalized journey planning could help alleviate uncertainty and anxiety. However, research indicates mixed evidence of success of such programs to support travel behavior change. A study by Thøgersen (2009) found that whether or not car owners in Copenhagen received customized travel planning assistance with their free month of public transport had no effect on travel behavior. In contrast, Friman et al. (2010), who provide an excellent review of evaluations of 'soft' transport policy measures, summarize a large number of European programs that show between 10 and 37\% increase in transit trips per person per year using IndiMark ${ }^{\circledR}$ programs, which provide personalized information, advice and incentives to promote travel behavior change. However the popularity of personalized journey planning has waned significantly since its zenith in the early 2000s (James 2017).

Some of the errors that participants described encountering when undertaking unfamiliar travel, such as missing stops and taking wrong services, would have actually made their journeys much longer. It seems reasonable to assume that this process may be impacting their perception of how long it takes to travel somewhere by transit. This could dissuade them from using transit into the future when in fact the discrepancies in travel time between transit and car may not be as great as people perceive.

It is interesting to consider the adaptations and optimization that were observed to occur. There may be a way to speed up the process of optimization by providing more information to people about service intricacies. For example, a smartphone app could be developed to provide hints about services, such as the ideal place to sit on the train for a quick exit, or other services that they could use to complete their journey if there are any service disruptions.

Despite the important findings from this research, as with all research methods, there are some limitations associated with the interviews. The main limitation is that interview participants were generally students and staff of Monash University; and although a range of trip types were discussed, the sample population represents a highly educated and privileged segment of the population. It will not capture, for example, the specialized needs of important segments of the transit-riding population such as the elderly, lowincome or physically disabled people. However, the research still proposes some important frameworks for understanding unfamiliar journeys which can be further explored in future research. Further research on unfamiliar transit travel and learning to use systems in a wider range of cities, suburbs, rural areas and different countries may prove beneficial. In particular, it would be useful to analyze the experiences of travelers who do not speak English or other relatively common languages.

There are also some other facets of unfamiliar transit travel that would benefit from more in-depth exploration in future research. For instance, because the interviews were 
one-off, they were not structured to review specific timescales related to learning and habituation. Dziekan (2008) found it took 7 weeks to habituate to travel in a completely new city; it is not clear how much faster people habituate to more familiar circumstances (such as using a new mode in a familiar city).

In addition, this framework was developed in the context of pre-planned unfamiliar transit trips (e.g. after bringing a car in for a service). It would be worthwhile to conduct a similar in-depth investigation of the process that is undertaken during unplanned disruptions to familiar transit trips (such as a significant transit system failure). The parallels are clear as during unplanned disruptions, passengers are likely experiencing a great deal of anxiety and they require additional information to complete their journey (Passenger Focus 2011; Pender et al. 2014).

All habitual transit travelers were, at one point, unfamiliar travelers. Studies such as this one provide important insights into this key market and can help transit authorities better understand their customer base.

Acknowledgements This research was made possible by the generous funding and assistance of Public Transport Victoria (PTV). Any omissions or errors in the paper are the responsibility of the authors. A version of this paper was presented at the 2016 World Conference in Transport Research.

Authors' contribution LS: Literature search and review, conducted interviews, analyzed results, manuscript writing and editing. AD: Conceptual guidance, manuscript writing and editing. GC: Conceptual guidance, manuscript editing.

\section{Compliance with ethical standards}

Conflict of interest On behalf of all authors, the corresponding author states that there is no conflict of interest in the preparation of this manuscript.

Open Access This article is distributed under the terms of the Creative Commons Attribution 4.0 International License (http://creativecommons.org/licenses/by/4.0/), which permits unrestricted use, distribution, and reproduction in any medium, provided you give appropriate credit to the original author(s) and the source, provide a link to the Creative Commons license, and indicate if changes were made.

\section{References}

Bamberg, S., Schmidt, P.: Regulating transport: behavioural changes is the field. J. Consum. Policy 22(4), 479-509 (1999)

Banister, D.: The sustainable mobility paradigm. Transp. Policy 15(2), 73-80 (2008)

Beige, S., Axhausen, K.W.: Interdependencies between turning points in life and long-term mobility decisions. Transportation 39(4), 857-872 (2012)

Beirão, G., Sarsfield Cabral, J.A.: Understanding attitudes towards public transport and private car: a qualitative study. Transp. Policy 14(6), 478-489 (2007)

Bovy, P.H.L., Stern, E.: Route Choice: Wayfinding in Transport Networks. Kluwer Academic Publishers, Dordrecht (1990)

Charmaz, K.: Grounded Theory. In: Smith, J.A., Rom, H., Langenhove, L.V. (eds.) Rethinking Research Methods, pp. 27-49. SAGE, Thousand Oaks (1995)

Charmaz, K.: Constructing Grounded Theory: A Practical Guide Through Qualitative Research. SagePublications Ltd, London (2006)

Chatterjee, K., Ma, K.R.: Time taken for residents to adopt a new public transport service: examining heterogeneity through duration modelling. Transportation 36(1), 1-25 (2009)

Clark, B., Chatterjee, K., Melia, S., Knies, G., Laurie, H.: Life events and travel behavior: exploring the interrelationship using UK household longitudinal study data. Transp. Res. Rec. J. Transp. Res. Board 2413, 54-64 (2014) 
Dziekan, K.: The transit experience of newcomers to a city: learning phases, system difficulties and information search strategies. 87th TRB Meeting, Washington DC (2008)

Dziekan, K., Dicke-Ogenia, M.: Reducing uncertainty and supporting cognitive maps in travel information for public transport. World Rev. Intermodal Transp. Res. 3(1-2), 73-90 (2010)

Friman, M., Richter, J., Gärling, T.: Review of implementations of soft transport policy measures. Transp. Theory Appl. 2(1), 5-18 (2010)

Fujii, S., Garling, T., Kitamura, R.: Changes in drivers' perceptions and use of public transport during a freeway closure: effects of temporary structural change on cooperation in a real-life social dilemma. Environ. Behav. 33(GEOBASE), 796-808 (2001)

Gould, J., Zhou, J.: Social experiment to encourage drive-alone commuters to try transit. Transp. Res. Rec. 2144, 93-101 (2010)

James, B.: TravelSmart: An Obituary and Epitaph. Australasian Transport Research Forum, Auckland (2017)

Klockner, C.A., Matthies, E.: How habits interfere with norm-directed behaviour: a normative decisionmaking model for travel mode choice. J. Environ. Psychol. 24(3), 319-327 (2004)

Kuhnimhof, T., Chlond, B., von der Ruhren, S.: Users of transport modes and multimodal travel behavior steps toward understanding travelers' options and choices. Transp. Res. Rec. J. Transp. Res. Board 1985, 40-48 (2006)

Lane, B.W.: The relationship between recent gasoline price fluctuations and transit ridership in major US cities. J. Transp. Geogr. 18(2), 214-225 (2010)

Le-Klähn, D.-T., Gerike, R., Michael Hall, C.: Visitor users vs. non-users of public transport: the case of Munich, Germany. J. Destin. Mark. Manag. 3, 152-161 (2014)

Morse, J.M.: Developing Grounded Theory: The Second Generation. Left Coast Press, Walnut Creek (2009)

Nordlund, A., Westin, K.: Influence of values, beliefs, and age on intention to travel by a new railway line under construction in northern Sweden. Transp. Res. Part A Policy Pract. 48, 86-95 (2013)

Passenger Focus: Information: rail passengers needs during unplanned disruption-qualitative research. London (2011)

Pender, B., Currie, G., Delbosc, A., Shiwakoti, N.: Social media use during unplanned transit network disruptions: a review of literature. Transp. Rev. 34(4), 501-521 (2014)

Prestopnik, J.L., Roskos-Ewoldsen, B.: The relations among wayfinding strategy use, sense of direction, sex, familiarity, and wayfinding ability. J. Environ. Psychol. 20(2), 177-191 (2000)

Ramadurai, G., Srinivasan, K.K.: Dynamics and variability in within-day mode choice decisions-role of state dependence, habit persistence, and unobserved heterogeneity. Travel Demand Land Use 1977, 43-52 (2006)

Schmitt, L., Currie, G., Delbosc, A.: Measuring the impact of unfamiliar transit travel using a university access survey. Transp. Policy 30, 301-307 (2013)

Schmitt, L., Currie, G., Delbosc, A.: Lost in transit? Unfamiliar public transport travel explored using a journey planner web survey. Transportation 42(1), 101-122 (2015)

Stradling, S.G.: Transport user needs and marketing public transport. Proc. Inst. Civ. Eng. Munic. Eng. 151(1), 23-28 (2002)

Taylor, M.A.P.: Voluntary travel behavior change programs in Australia: the carrot rather than the stick in travel demand management. Int. J. Sustain. Transp. 1(3), 173-192 (2007)

Thøgersen, J.: Promoting public transport as a subscription service: effects of a free month travel card. Transp. Policy 16(6), 335-343 (2009)

Verplanken, B.: Beyond frequency: habit as mental construct. Br. J. Soc. Psychol. 45(3), 639-656 (2006)

Verplanken, B., Aarts, H.: Habit, attitude, and planned behaviour: is habit an empty construct or an interesting case of goal-directed automaticity? Eur. Rev. Soc. Psychol. 10(1), 101-134 (1999)

Verplanken, B., Aarts, H., Vanknippenberg, A., Vanknippenberg, C.: Attitude versus general habit-antecedents of travel mode choice. J. Appl. Soc. Psychol. 24(4), 285-300 (1994)

Dr Lorelei Schmitt is sustainable transport planner in New Zealand with more than 10 years' experience in transport and land use planning projects and research. She has a history of providing high quality advice on a variety of transport projects across New Zealand and Australia. Her doctoral thesis on unfamiliar transit travel was sponsored by Monash University and Public Transport Victoria in Melbourne.

Dr Alexa Delbosc is a Senior Lecturer at the Monash Institute of Transport Studies in the Department of Civil Engineering. She draws from her research-based Master's in social psychology from Harvard University and $\mathrm{PhD}$ in Transport from Monash University to study public transport, travel behaviour and the changing travel habits of young people. 
Professor Graham Currie is a renowned international public transport research leader and policy adviser with over 30 years' experience. He is the director of the Public Transport Research Group (PTRG) in the Monash University Department of Civil Engineering. In 2017 Professor Currie was elected as a Fellow of the Academy of Technology, Science and Engineering (ATSE). 